\title{
Photovoltaic Status and Research on Remote Monitoring Information Transmission
}

\author{
Xiaohong Duan ${ }^{1, a}$, Fengjie Sun ${ }^{2, b}$, Wenjing $M^{3, c}$,Wenbing $L^{4, d}$, \\ Xiongwen Zhao ${ }^{5, e}$ \\ School of Electrical and Electronic Engineering,North China Electric Power University, Beijing,
102206, China \\ a1287084464@qq.com, bsfj@ncepu.edu.cn, '86245459@qq.com, djiaoshijie@vip.sina.com, \\ ehuadian_zhaoxw@126.com
}

Keywords: Solar energy; Distributed grid-connected PV; Remote monitoring;Communication mode

\begin{abstract}
Photovoltaic (PV) has the advantage of safe, reliable, clean, easy maintenance and so on. This paper analyzes the natural conditions of solar energy resources in Qingdao .The local application situation and development trend of PV are also discussed. At the same time, in order to meet the needs of operation and management for distributed PV substations, remote monitoring information transmission scheme is designed based on fiber-optic, GPRS and other methods of communication, which creates favorable conditions for the construction of PV plants and optimal operation management in Qingdao.
\end{abstract}

\section{Introduction}

With the increasing of the global energy shortage and environmental problems, PV has become an emerging industry that countries all over the world have generally concerned and developed because of its advantages of safe, reliable, non-polluting, less constrained, low failure rate, no noise, easy maintenance and so on. Abundant solar energy resources in Qingdao provide a broad development prospect for PV. In recent years, with the country's new energy policy supporting, the capacity of PV power generation increased rapidly. In order to optimize the operation of PV systems under the management of the grid, the establishment of remote monitoring system has great significance, of which the construction of the monitoring information transmission channel is an important part.

\section{The construction of PV in Qingdao}

Solar energy resources. According to the amount of solar radiation the area accepted, the country can be divided into five areas. One, two, three kinds are abundant or relatively rich areas in solar energy resources. These areas account for more than two-thirds of the nation's total area, which have the good condition of utilizing solar energy. Although the condition of solar energy resources is bad of four, five kinds, there is still some value. According to the statistics of meteorological department, Qingdao area, with annual solar radiation amount of $5020 \mathrm{MJ} / \mathrm{m}^{2} \cdot \mathrm{a}$ and annual average sunshine hours for 2541.1 hours,belongs to the third kind, in which solar energy resources are available.Besides, continuous rainy days are not common, basically with 2 days. From the natural conditions, the area is suitable for the development of solar PV power generation[1].

The analysis of the benefit for distributed PV. With the tilt of national and regional policies, solar PV projects of Huangdao district developed rapidly in the past two years. PV projects can not only effectively alleviate tensions in power during the peak hours, but also have remarkable benefits of energy saving and environmental protection. Economic and environmental benefits brought by distributed PV projects of $1 \mathrm{MW}$ are shown in Table 1. 
Table 1 Energy saving benefits of 1MW PV project in Huangdao district

\begin{tabular}{|c|l|c|c|c|c|c|}
\hline Project title & $\begin{array}{l}\text { Average } \\
\text { ennual } \\
\text { electricity } \\
\text { production } \\
\text { (million } \\
\text { kwh) }\end{array}$ & $\begin{array}{c}\text { Annual } \\
\text { electricity } \\
\text { savings } \\
\text { (yuan) }\end{array}$ & $\begin{array}{c}\text { Average } \\
\text { annual } \\
\text { savings of } \\
\text { standard } \\
\text { coal(tons) }\end{array}$ & $\begin{array}{c}\text { Average } \\
\text { annual } \\
\text { reduction } \\
\text { of CO2 } \\
\text { emissions } \\
\text { (tons) }\end{array}$ & $\begin{array}{c}\text { Average } \\
\text { annual } \\
\text { reduction } \\
\text { of SO2 } \\
\text { emissions } \\
\text { (tons) }\end{array}$ & $\begin{array}{c}\text { Average } \\
\text { annual } \\
\text { reduction of } \\
\text { nitrogen } \\
\text { oxides } \\
\text { (tons) }\end{array}$ \\
\hline $\begin{array}{c}\text { Distributed } \\
\text { PV projects } \\
\text { of 1MW }\end{array}$ & 1.05 & 790,000 & 357 & 893 & 5 & 3.6 \\
\hline
\end{tabular}

The current situation for the construction of PV power generation. According to the news learned from the Urban and Rural Construction Committee by daily reporter in Qingdao, seven projects in our city have been listed as a national "Golden Sun Demonstration Project" in 2012 by expert evaluation of Ministry of finance, ministry of science and technology, national energy administration and department of housing. The total installed capacity is $102.67 \mathrm{MW}$, which accounted for $70 \%$ of the whole province. The projects will receive state aid funds of 564.5 million yuan with user side PV projects subsidy standard of 5.5 yuan / watt, as shown in Table 2.

Table 2 Golden Sun Demonstration Project List of Qingdao in 2012

\begin{tabular}{|c|c|c|c|}
\hline Project title & $\begin{array}{c}\text { Installed } \\
\text { capacity }(\mathrm{kw})\end{array}$ & $\begin{array}{l}\text { State } \\
\text { subsidies } \\
\text { (million) }\end{array}$ & The project owner \\
\hline $\begin{array}{l}\text { Golden Sun Demonstration Projects of } \\
\text { CECEP vehicles and parts Qingdao } \\
\text { Industrial Zone }\end{array}$ & 20000 & 11000 & $\begin{array}{l}\text { CECEP Solar Energy } \\
\text { Technology Co., Ltd }\end{array}$ \\
\hline $\begin{array}{l}\text { The Golden Sun Demonstration Project of } \\
\text { Pingdu Economic Development Zone }\end{array}$ & 15009 & 8254.95 & $\begin{array}{l}\text { Datang Shandong } \\
\text { Power Generation } \\
\text { Co., Ltd. }\end{array}$ \\
\hline $\begin{array}{c}\text { Greenhouse PV Demonstration Project of } \\
\text { Qingdao New Energy Solutions } \\
\text { Inc.(NESI) }\end{array}$ & 20000 & 11000 & $\begin{array}{l}\text { Qingdao New } \\
\text { Energy Solutions } \\
\text { Inc.(NESI) }\end{array}$ \\
\hline Rooftop PV Projects of Qingdao Xiao Tian & 7660 & 4213 & $\begin{array}{l}\text { Qingdao New } \\
\text { Energy Solutions } \\
\text { Inc.(NESI) }\end{array}$ \\
\hline $\begin{array}{l}\text { The Second Golden Sun Demonstration } \\
\text { Project of Sailun Industrial Park }\end{array}$ & 5000 & 2750 & Sailun Co.,Ltd. \\
\hline $\begin{array}{l}\text { Gold Sun Concentrated Application } \\
\text { Demonstration Project of Qingdao Bonded }\end{array}$ & 15000 & 8250 & $\begin{array}{l}\text { Qingdao Huakong } \\
\text { Energy Technology } \\
\text { Co., Ltd. }\end{array}$ \\
\hline $\begin{array}{c}\text { Golden Sun Demonstration Project of } \\
\text { Haier Industrial Park }\end{array}$ & 20000 & 11000 & $\begin{array}{l}\text { Qingdao Huakong } \\
\text { Energy Technology } \\
\text { Co., Ltd. }\end{array}$ \\
\hline
\end{tabular}

In addition, solar PV projects of Huangdao district developed rapidly in the past two years. Seven distributed solar PV projects have been completed by 2014, with a total installed capacity of 27.5 MW and investments of about 280 million yuan, and now have reached grid-connected PV power generation standards.Also,six distributed solar PV projects are under construction with a total installed capacity of $8.9 \mathrm{MW}$ and investments of about 80 million yuan, which is expected to be completed by the end of 2014. 
The problems of PV development and the necessity of remote monitoring. Although the development of PV in Qingdao has made significant progress, there are still some problems, such as difficulties of financing, grid connection and long payback period. What makes people more concerned is that for the cottage users, even though great efforts are spent to build distributed PV on the roof, they may also face demolition problems after a few years. Although "zero breakthrough" news of individual self-generating project came one after another, those are just some of the demonstration projects. The real commercial of distributed PV projects is rare and demonstration effect is not strong. Because the power system is in a gradual increase in intelligence, in order to grasp the real-time operational status of intelligent power stations to meet the needs of distributed PV operation and management, the establishment of the monitoring system of distributed PV power plant is necessary. The construction of the information transmission channel is one of the very important aspects.

\section{The composition of distributed PV remote monitoring system and the analysis of information transmission means}

The composition of distributed grid-connected PV remote monitoring system. PV monitoring system includes inverters, junction boxes, environmental testers, meters and other equipment that are connected by data cable to collect data to the monitoring data collector. After the collector sorting and analyzing these data, the data is uploaded to the network via Ethernet, GPRS and other means. User administrators can view the monitoring data on the Internet So that it is convenient for user administrators to view and manage the real-time data of the running PV power plants.PV grid monitoring system is shown in Fig. 1 [2].

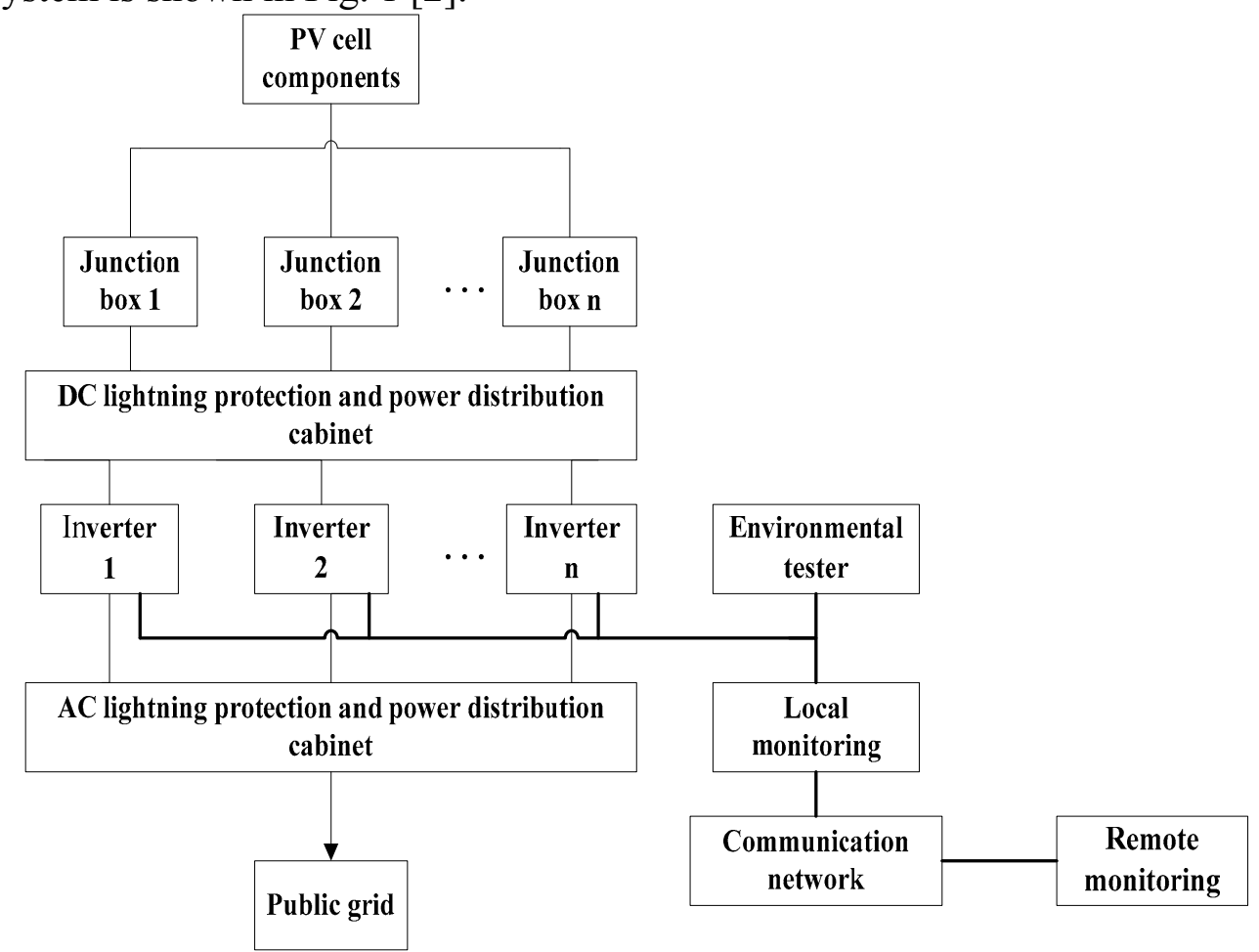

Fig. 1 Distributed grid-connected PV remote monitoring system

The analysis of information transmission means. Comparison of commonly used way of communication in communication effect and maintenance work is shown in the Table 3. 
Table 3 Comparison of commonly used way of communication

\begin{tabular}{|c|c|c|c|c|c|c|}
\hline $\begin{array}{c}\text { communication } \\
\text { mode }\end{array}$ & $\begin{array}{c}\text { Investment } \\
\text { costs }\end{array}$ & $\begin{array}{c}\text { Operatin } \\
\mathrm{g} \text { costs }\end{array}$ & $\begin{array}{c}\text { Constructio } \\
\mathrm{n} \text { period }\end{array}$ & $\begin{array}{c}\text { Maintenanc } \\
\text { e work }\end{array}$ & Immunity & $\begin{array}{c}\text { Transmission } \\
\text { rate }\end{array}$ \\
\hline Telephone line & middle & high & middle & middle & better & higher \\
\hline Optical fiber & high & low & long & middle & very well & high \\
\hline Cable & middle & low & long & high & better & middle \\
\hline $\begin{array}{c}\text { Wireless public } \\
\text { network }\end{array}$ & low & low & middle & high & bad & low \\
\hline $\begin{array}{c}\text { Power line } \\
\text { communication }\end{array}$ & low & low & short & short & worse & lower \\
\hline
\end{tabular}

From Table 1 we can see that the optical fiber has advantages of wide bandwidth, high transmission rate, long transmission distance and excellent performance. With the development of optical network technology, construction costs of PON have been significantly reduced. PON has become a mainstream technology of distribution network communication.However, with wide coverage and complex access environment of distribution network communication, some remote sites do not have the pipeline resources to lay fiber optic cable, or a high cost of laying alone and low flexibility, other means of communication are needed to serve as an effective complement.

Wireless communication is not subject to regional restriction, without wiring, small investment and fast construction speed. But there exsists the signal blind area and information security problems.Reliability is not high. Wireless public network communication method is more suitable for a complementary way.

Power line carrier (PLC) has a low cost, but the channel characteristics are complex and transmission rate is low. Two way automatic communication system(TWACS) is capable of long-distance communications across the distribution transformer. If proper technological methods are taken to enhance the communication rate, power line communication can play an important role.

By contrast, Telephone lines and cables are more reliable and the transmission rate is better, but the investment costs and labor inputs are higher[3,4].

\section{Design of information transmission scheme for distributed PV monitoring system}

With the development of communication technology, there are more and more communication technology solutions can choose, and each has advantages and disadvantages. However, there are so many distributed PV sites which are widely distributed and are installed in complex environment that a single form of communication can not solve the problem of distributed grid-connected PV accessing to the power distribution network with full coverage, economic and secure access [3].

According to the construction of PV power plants in Qingdao, all $35 \mathrm{kV}$ and above substations have basically realized the optical fiber communication at present.Extra communication interfaces have been reserved in the substation.For medium or large PV power plants located in the city center or urban district, optical fiber is choosed to achieve the connection considering reliability and security. For some remote sites that do not have the pipeline resources to lay fiber optic cable, or a high cost of laying alone, GPRS is a proper choice.

Currently, foe more and more residents PV projects and the low-pressure micro PV projects without laying fiber optic cable, GPRS communications is more suitable considering the economic costs. While some micro and small PV power plants located in remote mountainous areas without wireless signal can use TWACS to realize.

In addition, the communication mode between the injuction box and concentrator uses PLC communications because of its low costs, always online, within a wide range and high flexibility to overcome the shortcomings of RS-485 with high cost and difficult to maintain. Mixed communication scheme not only takes into account the economy but its stability and reliability performance as well. Design of information transmission scheme for distributed PV monitoring system is shown in Fig. 2. 


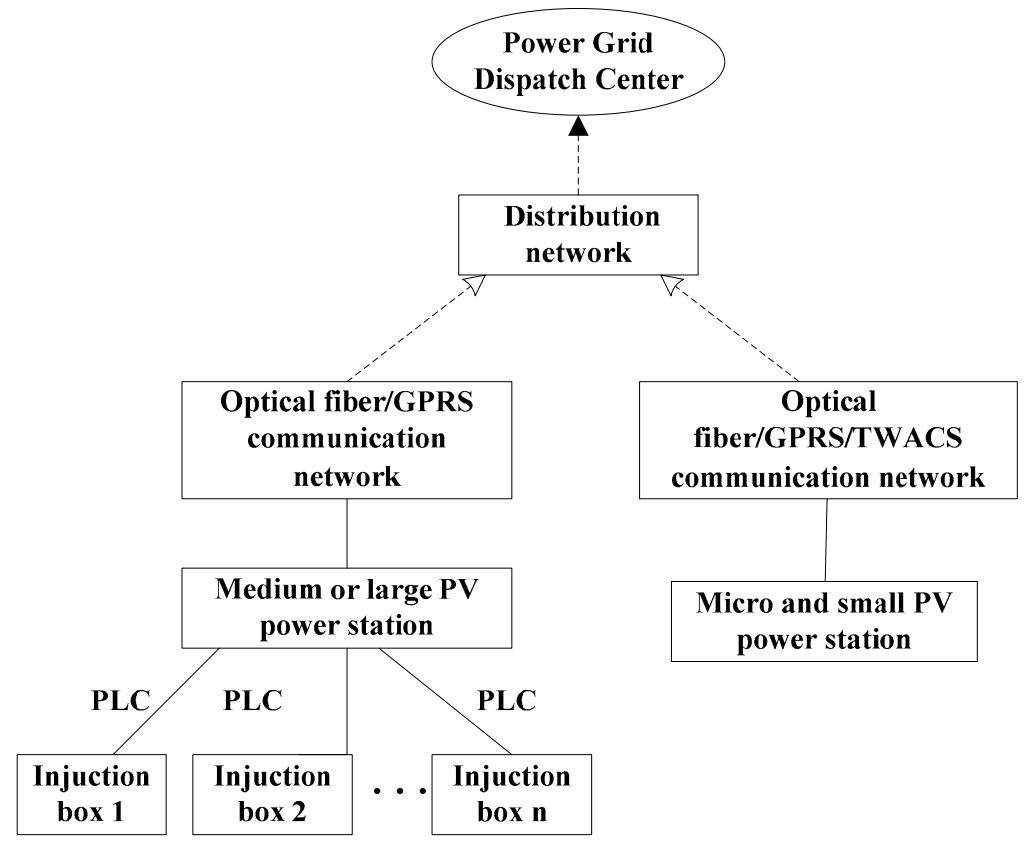

Fig. 2 Design of information transmission scheme for distributed PV monitoring system

\section{Summary}

This paper analyzes the construction situation of PV in Qingdao and characteristics of various communication technologies by contrast.Then, according to the communication requirements of distributed PV power generation system and the characteristics of the system itself, hybrid data transmission system that fiber optic serves as backbone communication network and GPRS wireless communication, TWACS, PLC serve as complementary way is designed.The program has a high reliability, flexibility, and can adapt better to the distributed PV systems and meet the requirements of remote monitoring.Thus favorable conditions for the promotion and application of PV power generation are created.

\section{References}

[1] Chu Xianfeng, Huang Xiang, Wang Yan, Jiao Guosong, Wang Jianhua, etc.Analysis of the direction and proposed promotion of solar energy photovoltaic generation in Qingdao[J] . Environmental Science and Management, 2009,34 (1):124-139.

[2] Zhang Guizhi, Luo Zhencheng, Zhang Yang. Photovoltaic status in Zhangjiakou and research on grid monitoring technology[J].Youth, 2013,(23):484.

[3] Zheng Weijun, Feng Xiaozhen. Communication technology for distributed grid-connected PV access to distribution network [J].Rural Electrification, 2014, (5): 7-8.

[4] Liu Zhongfang.The application of PLC technology in photovoltaic power generation system [M].Beijing: Beijing Jiaotong University, 2012.

[5] Xie Zhihan. The access of distributed photovoltaic power station and research on its protection and control system in Hangzhou area[M]. Baoding: North China Electric Power University, 2013. 